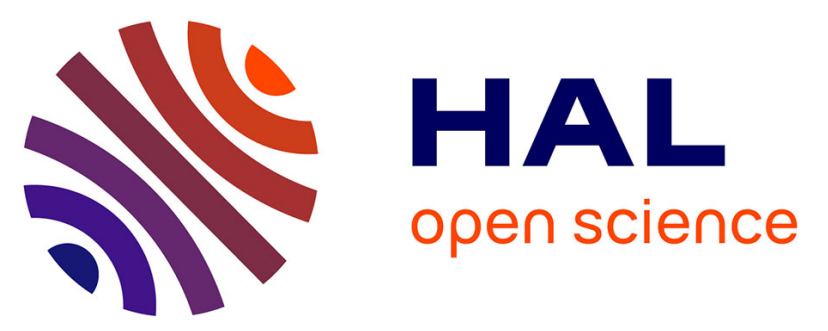

\title{
East China summer rainfall variability of 1958-2000: Dynamical downscaling with a variable-resolution AGCM
}

\author{
L. Zou, T. Zhou, Laurent Li, J. Zhang
}

\section{- To cite this version:}

L. Zou, T. Zhou, Laurent Li, J. Zhang. East China summer rainfall variability of 1958-2000: Dynamical downscaling with a variable-resolution AGCM. Journal of Climate, 2010, 23 (23), pp.6394-6408. 10.1175/2010jcli3689.1 . hal-01136864

\section{HAL Id: hal-01136864 \\ https://hal.science/hal-01136864}

Submitted on 30 Mar 2015

HAL is a multi-disciplinary open access archive for the deposit and dissemination of scientific research documents, whether they are published or not. The documents may come from teaching and research institutions in France or abroad, or from public or private research centers.
L'archive ouverte pluridisciplinaire HAL, est destinée au dépôt et à la diffusion de documents scientifiques de niveau recherche, publiés ou non, émanant des établissements d'enseignement et de recherche français ou étrangers, des laboratoires publics ou privés. 


\title{
East China Summer Rainfall Variability of 1958-2000: Dynamical Downscaling with a Variable-Resolution AGCM
}

\author{
LIWEI ZOU \\ LASG, Institute of Atmospheric Physics, and Graduate University, Chinese Academy of Sciences, Beijing, China
}

TIANJUN ZHOU

LASG, Institute of Atmospheric Physics, Chinese Academy of Sciences, Beijing, China

LAURENT LI

Laboratoire de Météorologie Dynamique, IPSL/CNRS, UPMC, Paris, France, and National Climate Center, China Meteorological Administration, Beijing, China

JIE ZHANG

LASG, Institute of Atmospheric Physics, and Graduate University, Chinese Academy of Sciences, Beijing, China

(Manuscript received 24 February 2010, in final form 6 July 2010)

\begin{abstract}
A variable-grid atmospheric general circulation model, namely, Laboratoire de Météorologie Dynamiquezoom, version 4 (LMDz4), with a local zoom over eastern China, is driven by 40-yr European Centre for Medium-Range Weather Forecasts (ECMWF) Re-Analysis (ERA-40) data and is used as a downscaling tool of summer rainfall variability for the period 1958-2000. During the integration, the model temperature and wind were nudged to the ERA-40 data through a relaxation procedure. The performance of the LMDz4 in simulating the regional rainfall features is thoroughly assessed through a comparison to both rain gauge data and the reanalysis product. The dynamical downscaling improves not only the climatology of the monsoon major rainband but also the interannual variability modes of rainfall over eastern China in comparison with that of the ERA-40 data. The added values of LMDz4 are evident in both the spatial patterns of dominant rainfall variability modes and the associated temporal variations. A comparison of rainfall averaged over several typical regions shows improvement as a better-matched variability and a reduced root-mean-square error, except for the region over the lower reaches of the Yellow River valley, where the model shows bias because of the northward shift of the monsoon rainband. This rainband shift is caused by the stronger low-level southerlies and the lower specific humidity over southern China. The stronger southwestern wind transports excessive water vapor northward, and the underestimation of specific humidity implies that air masses need to go farther north to reach condensation. Both favor a northward shift of the major rainband. The analysis demonstrates that a variable-resolution AGCM can be a useful tool for the dynamical downscaling of rainfall variability over eastern China, although the rainband bias remains evident as with many other regional climate models.
\end{abstract}

\section{Introduction}

East China is a unique region in the world, with its complex topography and landscapes. It is surrounded by the high Tibetan Plateau in the west and the western

Corresponding author address: Dr. Tianjun Zhou, LASG, Institute of Atmospheric Physics, Chinese Academy of Sciences, Beijing 100029, China.

E-mail: zhoutj@lasg.iap.ac.cn
Pacific Ocean in the east, as well as complex coastlines at its southeastern edge. The pronounced land-sea thermal contrast produces a robust monsoon climate. During summer, the rainfall is abundant and distributed in a quasi west-east rain belt comprising heavy rainstorms at meso- to microscales (Ding 1994). Atmospheric general circulation models (AGCMs) with coarse spatial resolution generally have difficulties in reproducing both the position and variation of the monsoon rainband (Kang et al.2002). A spurious precipitation center on the 
eastern periphery of the Tibetan Plateau is evident in many AGCMs (e.g., Yu et al. 2000). Recent studies indicated that both coupled and uncoupled global climate models generally show large biases in this domain (Zhou and Yu 2006; Zhou et al. 2009b; Chen et al. 2010), especially for the monsoon rainfall simulation (Zhou et al. 2008a; Li et al. 2010).

With better description of regional terrain and surface characteristics, regional climate models (RCMs) are useful tools to investigate regional climate [Giorgi and Mearns (1999); see also reviews by Leung et al. (2003) and Wang et al. (2004)]. RCMs have also been widely used in downscaling future climate change scenario projections made by global climate system models with coarse resolution (Gao et al. 2001, 2002, 2006; Christensen et al. 2007). Many regions of the world are the subject of studies with regional climate models. A few international coordinated efforts are carried out, focusing on different regions, such as the North American Regional Climate Change Assessment Program (NARCCAP) for North America (available online at http://www.narccap. ucar.edu/), Prediction of Regional Scenarios and Uncertainties for Defining European Climate Change Risks and Effects (PRUDENCE) program for Europe (available online at http://prudence.dmi.dk/), and Regional Climate Model Intercomparison Project (RMIP) for East Asia (Fu et al. 2005).

RCMs currently used in the climate modeling community can be either limited-area models or variablegrid global models with resolution enhancement over the target region. For the first category, the well-known models include the fifth-generation Pennsylvania State University-National Center for Atmospheric Research Mesoscale Model (MM5; e.g., Liang et al. 2004a,b, 2007; Zhu and Liang 2005, 2007) and the Abdus Salam International Centre for Theoretical Physics (ICTP) Regional Climate Model (RegCM; e.g., Giorgi et al. 2004). Efforts have also been devoted to the development of an RCM named the climate version of the Advanced Regional Eta-Coordinate Model (CREM) by the Chinese Academy of Sciences (Shi et al. 2009). RCMs have been extensively used for studying climate variation and change in China (e.g., Lee and Suh 2000; Li and Ding 2005; Feng and Fu 2006; Qian and Leung 2007; Gao et al. 2008). For the second category, many studies are also reported in the literature for North America (e.g., Fox-Rabinovitz et al. 2001, 2006), northern Europe (Barstad et al. 2009), and the Mediterranean (Gibelin and Déqué 2003; Goubanova and $\mathrm{Li}$ 2007). However, the performance of such an approach over East Asia is less well known.

In this study we perform a variable-resolution GCM [Laboratoire de Météorologie Dynamique-zoom version 4 (LMDz4)] simulation that has a zoom centered in eastern China. The employed methodology consists of forcing LMDz4 beyond the zoomed domain by observed atmospheric circulations. Since such a modeling approach is rather new in simulating regional climate in China, its significance should be examined. The main purpose of this study is to validate the model and to show the added values of LMDz4 for climate downscaling. Climate variability simulated inside the zoom domain is used to validate the model by a comparison with the observed climate variables. The added values of the regional model are assessed by a comparison with the low-resolution driving fields.

The rest of the paper is organized as follows. Section 2 presents a brief description of the LMDz4 model and experimental design. Results are analyzed in section 3, including an evaluation of model climatology and a comparison of the spatial structure and temporal evolution of the dominant empirical orthogonal function (EOF) modes of rainfall anomalies derived from the station observation, LMDz4 simulation, and 40-yr European Centre for Medium-Range Weather Forecasts (ECMWF) Re-Analysis (ERA-40). The precipitation time series derived from three datasets at regional scales are also compared in section 3. A discussion on the model bias is given in section 4 . The main findings are summarized in section 5 .

\section{Model description, experimental design, and analysis method}

\section{a. Model description}

The model used in this study is LMDz4, which was developed at Laboratoire de Météorologie Dynamique, France. The model is formulated in the finite difference grid, with 120 points in longitude, 91 points in latitude, and 19 hybrid layers in the vertical. The grid is stretchable, so that the model can be used for regional climate studies (Hourdin et al. 2006; Zhou and Li 2002). With respect to the previous version ( $\mathrm{Li}$ 1999), cloud, convection, and land surface schemes used in LMDz4 have been significantly revised. A generalized lognormal probability distribution function (Bony and Emanuel 2001) in the prognostic cloud scheme (Le Treut and Li 1991; Le Treut et al. 1994) has been introduced. The cumulus convective parameterization developed by Emanuel (1991) has been implemented. The bucket land surface model used in previous version has been replaced by the two-layer hydrological scheme of Organizing Carbon and Hydrology in Dynamic Ecosystems (ORCHIDEE), a complex surface and vegetation model (Krinner et al. 2005). More detailed information about the physical processes is given in Hourdin et al. (2006), which also 

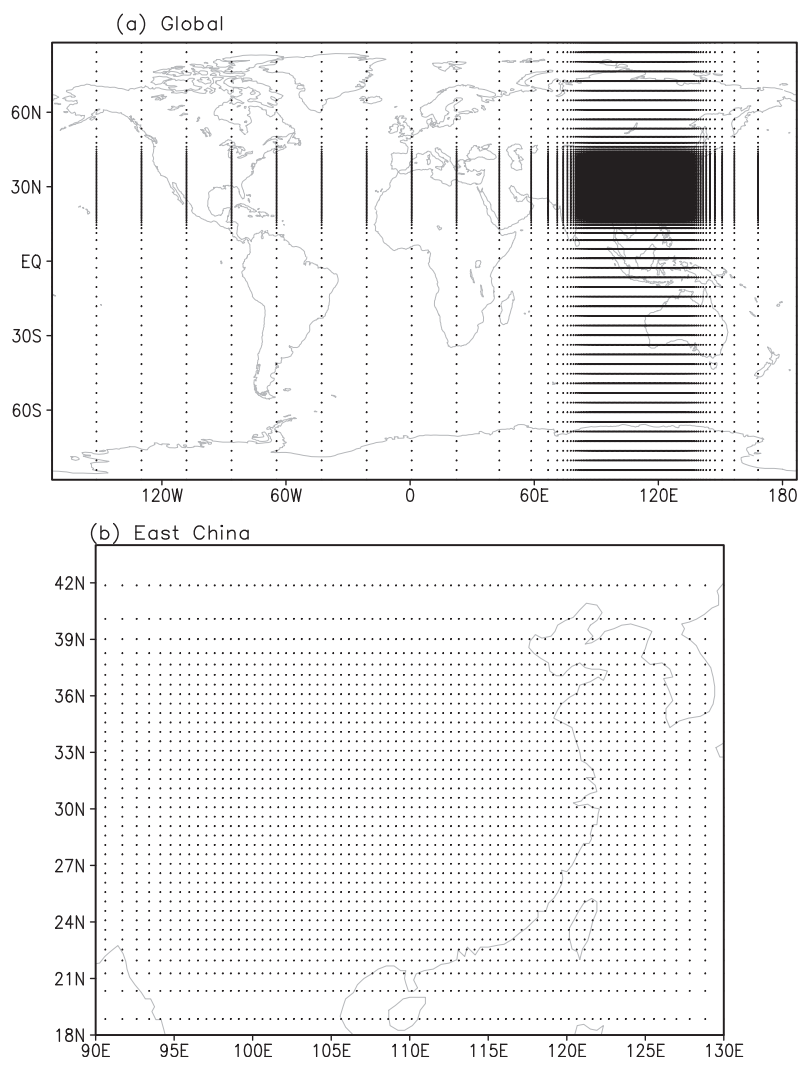

FIG. 1. Model grids for (a) the whole globe and (b) eastern China.

provides a preliminary assessment of the model performance on global scale.

When the zoom function is activated, LMDz4 can be run in two modes. The first one is like a normal global AGCM driven by sea surface temperature (SST) as lower-boundary conditions. There is no need to have any lateral boundary conditions. The second mode of operation (called LMDz4-regional) is close to that of a traditional limited-area model. The domain inside the zoom is free to have its own climate, but the domain outside (the rest of the world in complement to the zoom) is restored to observed values or to outputs of global models. The restoring is realized by an exponential relaxation procedure that is controlled by a time scale. The time scale varies geographically and can be independent of the zoom location itself. We chose the second mode in this study.

\section{b. Experiment design and data}

The local zoom used in this study is centered at $30^{\circ} \mathrm{N}$, $110^{\circ} \mathrm{E}$. The employed model grid is shown in Fig. 1 . The zoom domain $\left(20^{\circ}-40^{\circ} \mathrm{N}, 90^{\circ}-130^{\circ} \mathrm{E}\right)$ covers most of East China. The resolution is about $50 \mathrm{~km}$ in the zoom domain, and it becomes quickly coarser outside. A longterm continuous integration covering the period of
1958-2000 was performed. The driven data were from ERA-40 (Uppala et al. 2005). The time scale of relaxation is 10 days in the zoom domain, whereas it is half an hour outside the domain. The distinct contrast of the relaxation time scales implies that the model runs almost independently in the zoom domain, whereas it totally follows the forcing field outside the zoom domain. Note that we put a very long (10 days, but not infinite) relaxation time scale inside the zoom domain to ensure that the model has its own behaviors but also to go smoothly close to the driven forcing. This operation is quite similar to the concept of spectral nudging commonly used in limited-area models for climate downscaling purpose-but our nudging effect is very weak. The nudged variables include meridional wind, zonal wind, and temperature provided by ERA-40 (nearly $1.125^{\circ} \times 1.125^{\circ}$ with a Gaussian grid) at 6-h intervals. Note that the sea level pressure (SLP) and moisture, which are necessarily nudged in the conventional integration of limited-area models, are predicted by LMDz4 itself. The climatological mean SST and sea ice prescribed as sea surface boundary condition in the simulation are taken from the Met Office Hadley Centre (Rayner et al. 2006).

Monthly-mean rainfall based on surface meteorological stations for 1958-2000 and compiled by the China Meteorological Administration (CMA) is used as observational evidence for model evaluation. This dataset has been widely used in climate variability studies (e.g., Hu et al. 2003; Zhou and Yu 2005). The observed rainfall data used in this study are derived from 127 stations in eastern China. To validate the downscaling skill of LMDz4, the atmospheric circulation and rainfall data derived from ERA-40 (Uppala et al. 2005) are also used.

\section{c. Analysis method}

Compared to the original coarse resolution of ERA-40 data, that is, $1.125^{\circ} \times 1.125^{\circ}$, a higher-resolution (about $50 \mathrm{~km}$ ) product is obtained from the simulation. This kind of high-resolution "reanalysis" dataset provides potential benefits to many scientific and applied sectors (Lin et al. 2006). In the following analysis, in addition to a comparison of model results against the observational data, we also use the original ERA-40 as a benchmark, to examine the significance and improvement of the downscaling approach.

To reveal the spatial patterns of summer monsoon rainfall variation, EOF analysis is applied to June-August (JJA) mean precipitation anomalies from the station observation, LMDz4 simulation, and ERA-40. The EOF analyses were done on their own grid sizes. Composite analysis is used to show the spatial patterns of rainfall anomalies. The results from both the station observation 

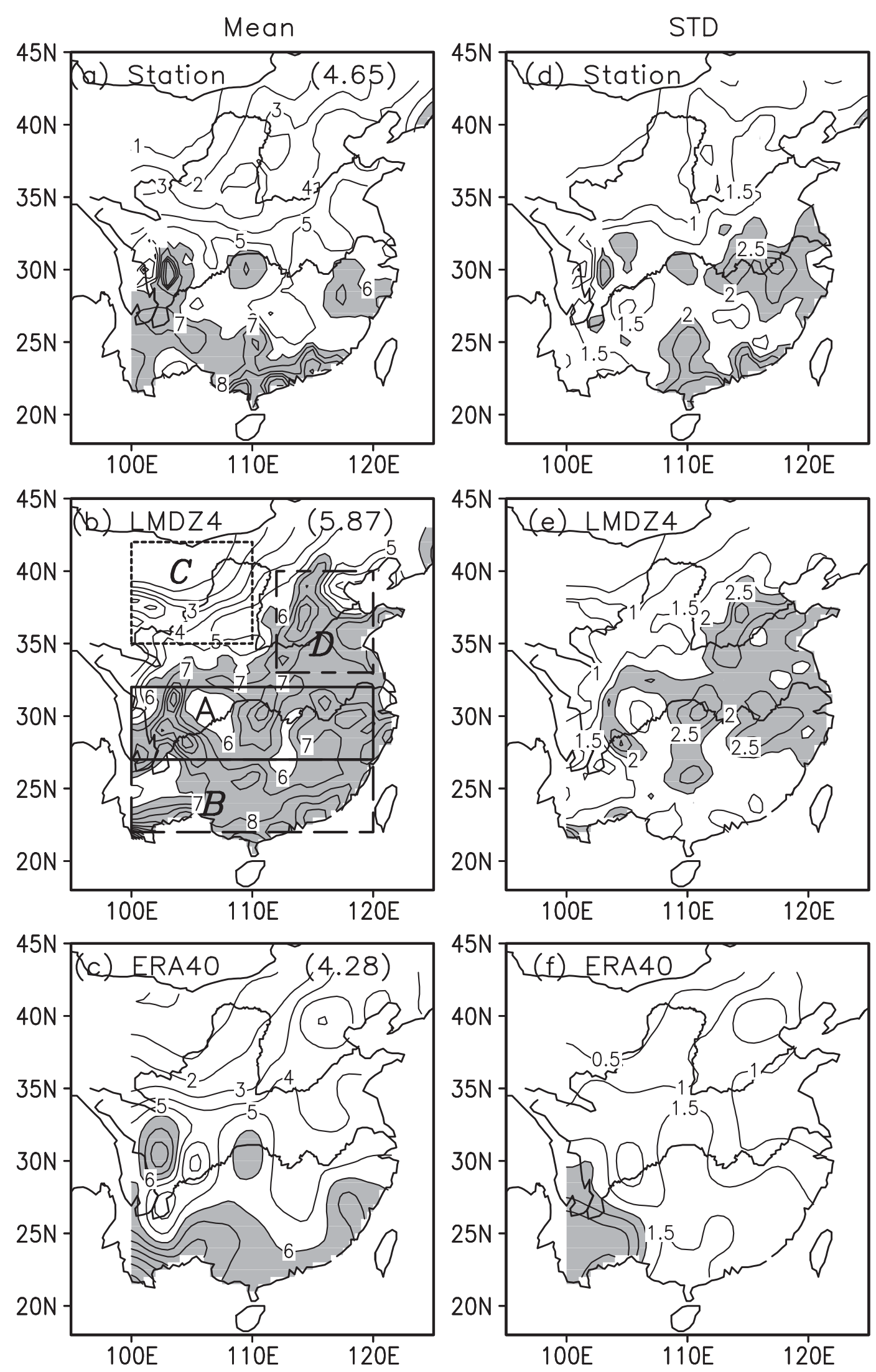


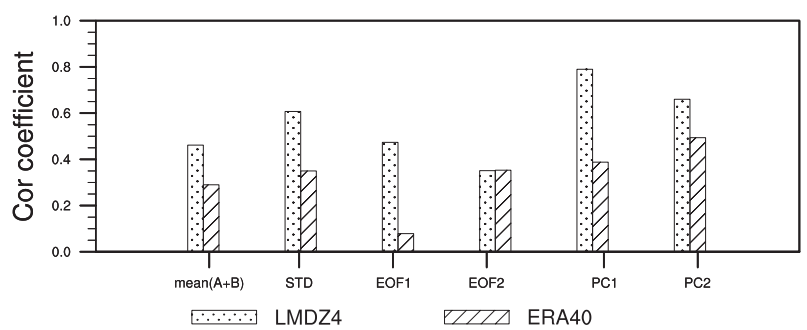

FIG. 3. Spatial pattern correlation coefficients (first four pairs) of mean rainfall over southern China (regions A and B in Fig. 2b), std, leading modes (EOF1 and EOF2) of rainfall between LMDz4 (or ERA-40 in second position of each pair), and station observation. Results from the station observation and ERA-40 are bilinearly interpolated into the grid of LMDz4 before calculating the spatial pattern correlation coefficient. Temporal correlation coefficients of PC1 and PC2 are also shown by the last two pairs of bars.

and ERA-40 are bilinearly interpolated to the model grid to calculate the spatial pattern correlation.

\section{Results}

\section{a. Mean state and leading modes of interannual variability of monsoon rainfall}

We begin our analysis from a comparison of JJA mean precipitation averaged during 1958-2000 (left panel of Fig. 2). The domain-averaged rainfall (Chinese mainland, south of $43^{\circ} \mathrm{N}$ and east of $100^{\circ} \mathrm{E}$ ) is $4.65,5.87$ and $4.28 \mathrm{~mm} \mathrm{day}^{-1}$ from the observations, LMDz4, and ERA-40, respectively. The rainfall intensity is slightly underestimated in ERA-40, whereas it is overestimated in LMDz4. In observation, the typical characteristic of monsoon rainfall over eastern China appears as a major rainband along the Yangtze River basin $\left(27^{\circ}-32^{\circ} \mathrm{N}, 100^{\circ}-\right.$ $120^{\circ} \mathrm{E}$; region A in Fig. $2 \mathrm{~b}$ ), a rainy climate in southeastern China $\left(22^{\circ}-27^{\circ} \mathrm{N}, 100^{\circ}-120^{\circ} \mathrm{E}\right.$; region B in Fig. $\left.2 \mathrm{~b}\right)$, and a semiarid climate in the upstream of the Yellow River valley $\left(35^{\circ}-42^{\circ} \mathrm{N}, 100^{\circ}-110^{\circ} \mathrm{E}\right.$; region $\mathrm{C}$ in Fig. $\left.2 \mathrm{~b}\right)$. These features are identified in both LMDz4 and ERA-40. LMDz4 shows its added values in the spatial pattern of major rainbands (regions A and B). The first two bars in Fig. 3 show the spatial correlation coefficients of rainfall between LMDz4 (ERA-40) and the observation. The pattern correlation coefficient of LMDz4 is higher than that of ERA-40, with 0.46 versus 0.29 .
The main deficiency of LMDz4 is the overestimation of rainfall intensity, especially over the lower reaches of the Yellow River valley $\left(33^{\circ}-40^{\circ} \mathrm{N}, 110^{\circ}-120^{\circ} \mathrm{E}\right.$; region $\mathrm{D}$ in Fig. 2b).

The standard deviation (std) of summer rainfall is shown in Fig. 2 (right panel). A strong variability is evident along the Yangtze River valley and in southeastern China. Regions with large std are generally consistent with regions having large mean rainfall. In LMDz4 (Fig. 2e), the std is underestimated in southeastern coastal China; however, it is overestimated in the lower reaches of the Yellow River valley, where the model produces excessive mean rainfall. ERA-40 has a low skill in capturing the typical characteristics of rainfall std. The second pair of bars in Fig. 3 reveals that the spatial pattern correlation coefficient between LMDz4 and the observation is higher than that between ERA-40 and the observation, with 0.61 versus 0.35 .

To further examine the interannual variability of monsoon rainfall in eastern China, we use the EOF analysis method to extract leading modes of variability. The first two leading modes derived from the observationLMDz4 and ERA-40-are shown in Figs. 4a-f. In the observation, the first mode (Fig. 4a) exhibits a meridional tripolar pattern, indicating that the changes of rainfall along the middle and lower reaches of the Yangtze River valley are generally accompanied by opposite changes in northern and southeastern China. This pattern is also shown in Huang et al. (2006) and Zhou and $\mathrm{Yu}$ (2005) despite the different length of samples employed in their EOF analysis. The second mode (Fig. 4b) represents an out-of-phase variation of precipitation anomalies between the Huaihe River valley $\left(30^{\circ}-35^{\circ} \mathrm{N}\right.$, $\left.105^{\circ}-120^{\circ} \mathrm{E}\right)$ and south of the Yangtze River $\left(22^{\circ}-30^{\circ} \mathrm{N}\right.$, $\left.105^{\circ}-120^{\circ} \mathrm{E}\right)$. This mode is also shown in Zhou and $\mathrm{Yu}$ (2005) and Han and Zhang (2009). These two modes, accounting for $15.5 \%$ and $12.9 \%$ of the total variance in the observation, respectively, correspond to the typical anomalous summer monsoon rainfall patterns defined by the National Climate Center of the CMA in operational short-term climate predictions, according to historical statistics (Zhao 1999; Zhou and Yu 2005).

The first two leading modes simulated by LMDz4 are shown in Figs. 4c,d. The EOF1 (EOF2) derived from the LMDz4 simulation corresponds to the EOF1 (EOF2)

FIG. 2. (left) JJA mean rainfall (with domain averages indicated in the upper-right corner of each plot, $\mathrm{mm} \mathrm{day}^{-1}$ ) and (right) interannual std of the JJA-mean rainfall $\left(\mathrm{mm} \mathrm{day}^{-1}\right)$ from (a),(d) station observations, (b),(e) LMDz4, and (c),(f) ERA-40. Shaded areas represent values larger than (left) $6 \mathrm{~mm}$ day $^{-1}$ and (right) $2 \mathrm{~mm} \mathrm{day}^{-1}$. Regions A-D denote $27^{\circ}-32^{\circ} \mathrm{N}, 100^{\circ}-120^{\circ} \mathrm{E} ; 22^{\circ}-27^{\circ} \mathrm{N}, 100^{\circ}-120^{\circ} \mathrm{E} ; 35^{\circ}-42^{\circ} \mathrm{N}, 100^{\circ}-110^{\circ} \mathrm{E}$; and $33^{\circ}-40^{\circ} \mathrm{N}, 110^{\circ}-120^{\circ} \mathrm{E}$, respectively. 
EOF 1

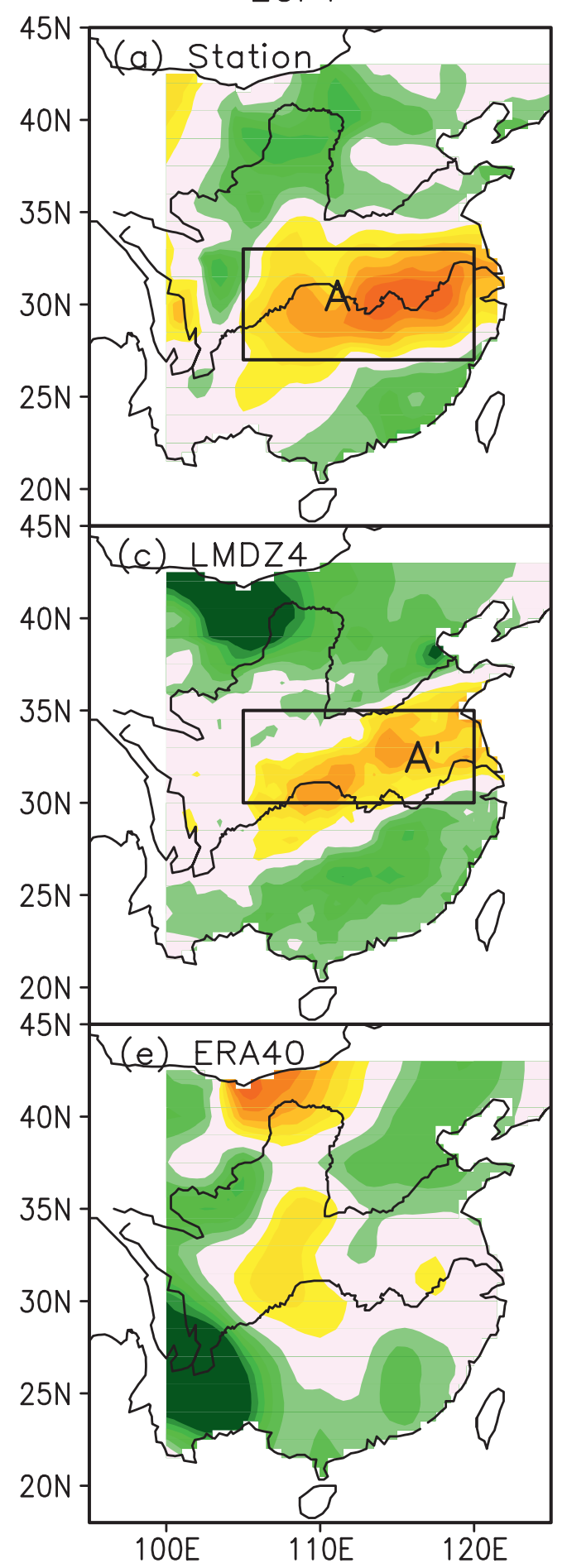

\section{EOF 2}

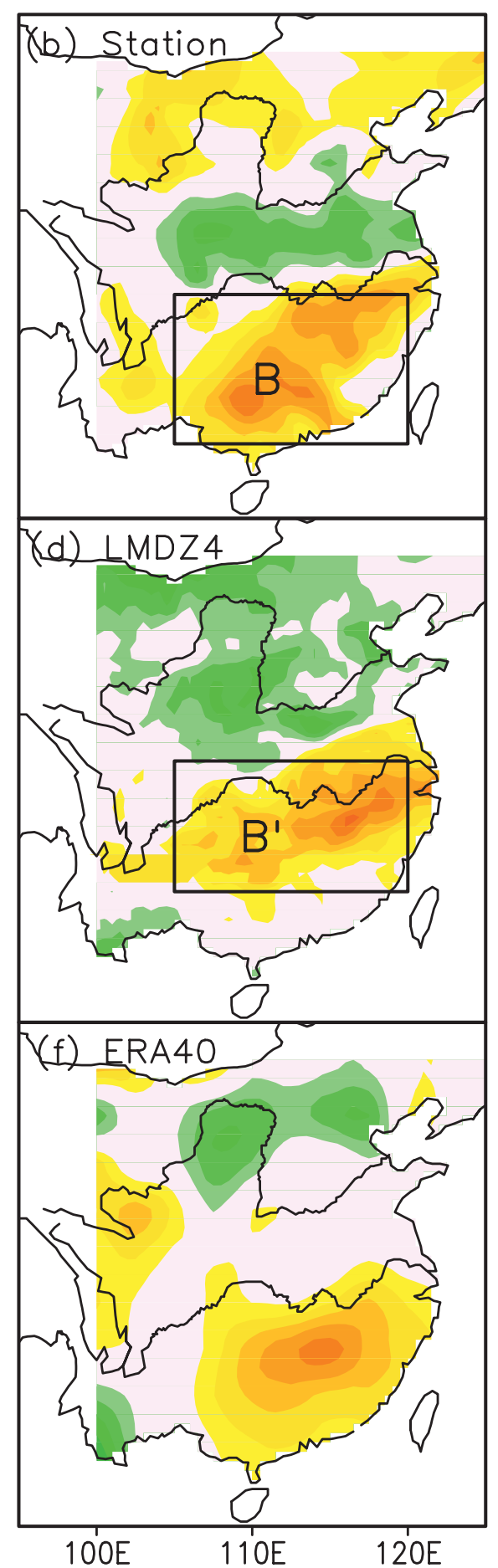

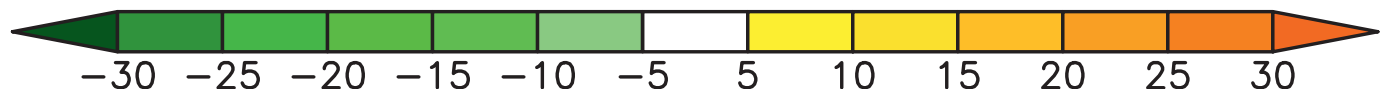

FIG. 4. The (left) first and (right) second leading modes of JJA mean rainfall for (a),(b) the station observation, (c),(d) LMDz4 simulation, and (e),(f) ERA-40. Patterns are shown as percentage of rainfall anomaly relative to mean state associated with 1 std of the corresponding PC. 

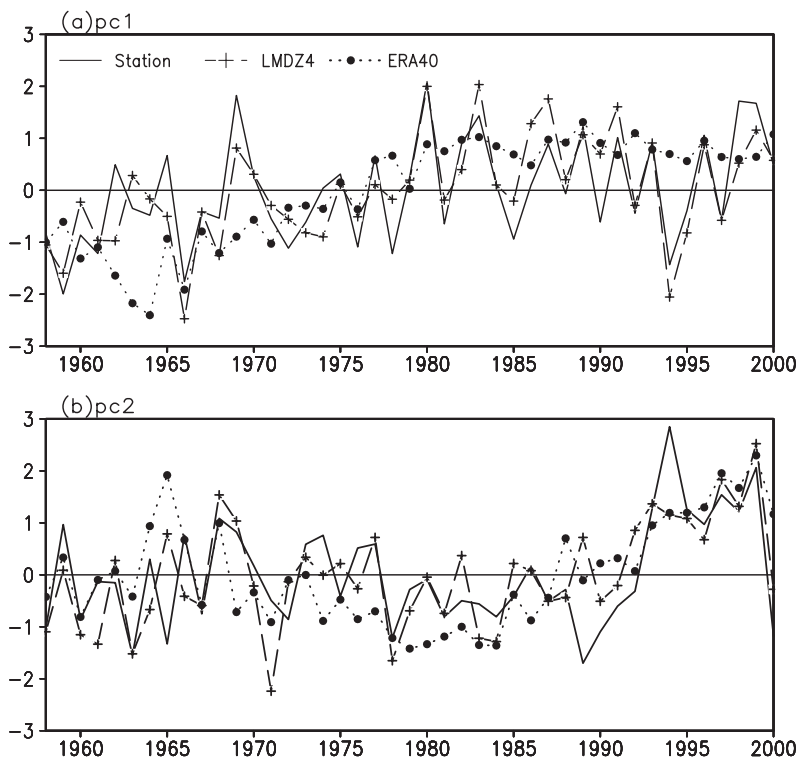

FIG. 5. Normalized PCs corresponding to the (a) first and (b) second leading modes for the observation, LMDz4, and ERA-40.

derived from the observation, which is confirmed by the patterns of simulated rainfall anomalies regressed upon the observed principal components of the two leading modes (figures not shown). The model is able to reproduce the meridional tripolar pattern in the first mode (Fig. 4c), as well as the out-of-phase relationship in the second mode (Fig. 4d). These two simulated modes have similar levels of statistical significance as the observed counterparts, namely, the EOF1 (EOF2) accounts for $13.9 \%(12.3 \%)$ of the total variance.

There are biases in the location of the anomaly centers. The rain belts associated with the first two leading modes shift northward in the model. For example, the positive anomaly center of EOF1 is located along the Yangtze River valley $\left(27^{\circ}-33^{\circ} \mathrm{N}, 105^{\circ}-120^{\circ} \mathrm{E}\right.$; region A in Fig. 4a) in the observation, but it shifts to the Huaihe River basin $\left(30^{\circ}-35^{\circ} \mathrm{N}, 105^{\circ}-120^{\circ} \mathrm{E}\right.$; region A in Fig. $\left.4 \mathrm{c}\right)$ in the simulation. For the second mode, the positive anomaly center is located in the south of the Yangtze River basin $\left(22^{\circ}-30^{\circ} \mathrm{N}, 105^{\circ}-120^{\circ} \mathrm{E}\right.$; region B in Fig. $\left.4 \mathrm{~b}\right)$ in the observation, but it shifts to the Yangtze River basin $\left(25^{\circ}-30^{\circ} \mathrm{N}, 105^{\circ}-120^{\circ} \mathrm{E}\right.$; region B in Fig. $\left.4 \mathrm{~d}\right)$ in the simulation. Another deficiency of the simulation is the underestimation of variance in southeastern coast of China. This is consistent with the small std values shown in Fig. 2b.

The tripolar pattern and the out-of-phase relationship are poorly reproduced in the reanalysis (Figs. 4e,f). The two dominant modes derived from the ERA-40 respectively account for $35.6 \%$ and $14.1 \%$ of the total variance, which are different from the observation. The spatial
TABLE 1. Positive- and negative-phase samples based on PC1 for composite analysis.

\begin{tabular}{lcc}
\hline \hline & $\begin{array}{c}\text { Positive-phase } \\
\text { years }\end{array}$ & $\begin{array}{c}\text { Negative-phase } \\
\text { years }\end{array}$ \\
\hline Observation & $1969,1980,1983$, & $1959,1961,1966,1972$, \\
& $1989,1991,1996$ & 1976,1994 \\
LMDz4 & $1980,1983,1986$, & $1959,1966,1968,1994$ \\
& $1987,1989,1991$ & \\
ERA-40 & $1983,1989,1992$ & $1958,1960,1961,1962,1963$, \\
& & $1964,1966,1968,1971$ \\
\hline
\end{tabular}

patterns of dominant modes are also different from their observed counterparts. For the leading mode, large loading is found over southwestern China in ERA-40 (Fig. 4e), while large loading is located along the middle and lower reaches of the Yangtze River valley in the observation (Fig. 4a). For the second mode, although both the location and fraction of the positive anomaly center are well reproduced in ERA-40 (Fig. 4f), the negative anomaly center shifts northward compared to the observed counterpart. The spatial correlation coefficients shown in Fig. 3 (the third and fourth pairs of bars) also indicate that both leading modes are better reproduced in LMDz4, especially for EOF1. The deficiencies of ERA-40 in capturing the leading modes of precipitation may be related to its insufficient resolution, which does not allow the model to correctly describe the mei-yu front and the associated monsoon rainband.

The corresponding normalized principal components (PCs) are shown in Fig. 5. The correlation coefficient of PC1 between the observation and the simulation is 0.79 , while that of the PC2 is 0.66 . Both of them are statistically significant at the $1 \%$ level. In addition, the observed PC2 shows decadal variation after 1990s (Fig. 5b), indicating that the rainfall in the southern portion of the Yangtze River valley has been increasing after 1990. This interdecadal variation is also reasonably simulated. The decadal variation of PCs is also well reproduced by ERA-40, but the performance for interannual variability is poor. The correlation coefficient of PC1 (PC2) between ERA-40 and the observation is 0.39 (0.49), which is lower than those of LMDz4 (last two pairs of

TABLE 2. As in Table 1, but for PC2.

\begin{tabular}{lcc}
\hline \hline & $\begin{array}{c}\text { Positive-phase } \\
\text { years }\end{array}$ & $\begin{array}{c}\text { Negative-phase } \\
\text { years }\end{array}$ \\
\hline Observation & $1968,1993,1994$, & $1958,1963,1965,1989$, \\
& 1995,1997 & 1990,2000 \\
LMDz4 & $1968,1969,1993,1994$, & $1960,1961,1963,1971$, \\
& $1995,1997,1998$ & $1978,1983,1984$ \\
ERA-40 & $1965,1994,1995,1996$, & $1978,1979,1980,1981$, \\
& $1997,1998,1999$ & 1983,1984 \\
\hline
\end{tabular}



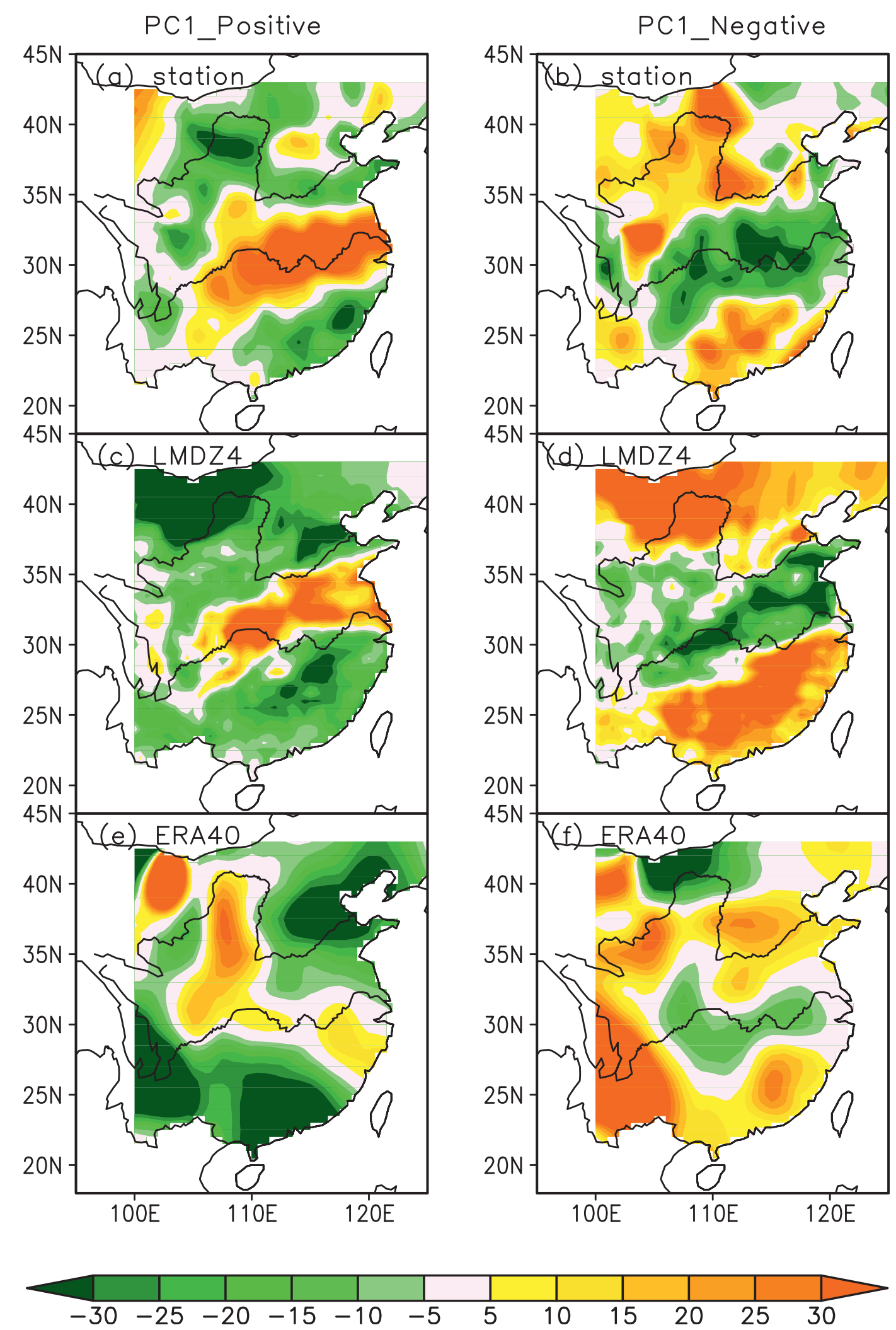

FIG. 6. Composite maps calculated from the first leading mode for the (a),(b) observation, (c),(d) LMDz4 simulation, and (e),(f) ERA-40. (left) Positive and (right) negative phases are depicted. Patterns are shown as percentage of rainfall anomaly relative to mean state. 
bars in Fig. 3), demonstrating the added values of the LMDz4.

Composite analysis is also performed to confirm the above leading modes revealed by EOF analysis. Positive and negative samples are selected based on the normalized values of PCs. The threshold used in the composite analysis is set to one standard deviation. A detailed description of the samples with respect to PC1 and PC2 are given in Tables 1, 2, respectively. Since EOF1 and EOF2 are orthogonal, the overlapping years are excluded from the corresponding composite samples. The composite fields based on PC1 are shown in Fig. 6. The tripolar pattern of observed EOF1 (Fig. 4a) is close to the composite maps of both positive samples (Fig. 6a) and negative samples (Fig. 6b). The rainfall anomalies in southern China $\left(22^{\circ}-27^{\circ} \mathrm{N}, 105^{\circ}-120^{\circ} \mathrm{E}\right)$ and northern China $\left(34^{\circ}-42^{\circ} \mathrm{N}, 105^{\circ}-120^{\circ} \mathrm{E}\right)$ vary oppositely with those along the Yangtze River valley $\left(27^{\circ}-32^{\circ} \mathrm{N}, 105^{\circ}-120^{\circ} \mathrm{E}\right)$. The composite maps based on LMDz4 also exhibit a tripolar pattern as the observed EOF1. However, the observed anomaly center in the Yangtze River valley shifts northward, and the anomaly center in northern China is exaggerated in the simulation. The composite maps based on ERA-40 also exhibit the main characteristics of the corresponding EOF1 (Fig. 4e), with large loading in southwestern China.

Composite fields corresponding to $\mathrm{PC} 2$ are shown in Fig. 7. In the observation, the out-of-phase relationship of rainfall anomalies between the Huaihe River valley $\left(30^{\circ}-35^{\circ} \mathrm{N}, 105^{\circ}-120^{\circ} \mathrm{E}\right)$ and south of the Yangtze River $\left(22^{\circ}-30^{\circ} \mathrm{N}, 105^{\circ}-120^{\circ} \mathrm{E}\right)$ projected onto EOF2 (Fig. $4 \mathrm{~b}$ ) is also obvious in the composite fields as expected. The composite pattern of the negative phase more closely resembles the EOF pattern than that of the positive phase. This is partly due to the strong negative phase of PC time series prior to the early 1990s shown in Fig. 5b. This characteristic is reasonably reproduced by LMDz4, although the simulated rainfall center shifts northward relative to the observation. The center of the composite fields based on ERA-40 is located in the region south of the Yangtze River, as its EOF2 pattern (Fig. 4f).

To investigate the temporal evolution of rainfall leading modes, the power spectra of PCs are shown in Fig. 8. In the observation, the first mode has a major spectral peak on $2.4 \mathrm{yr}$, a secondary peak on $3 \mathrm{yr}$, and a third peak on 8 yr (Fig. 8a). The quasi-biennial (QB; $2.7 \mathrm{yr}$ ) band of East Asian monsoon rainfall has been reported in many previous studies (e.g., Huang et al. 2006; Li et al. 2006; Zhou et al. 2008b). The Pacific-Japan teleconnection pattern is suggested to be the mechanism (Huang et al. 2006). The simulation captures the 2- and 3-yr peaks reasonably well, except for the weak 9-yr peak. The second mode in the observation has only one peak around $2.5 \mathrm{yr}$. The 2.5-yr peak is also reproduced in the simulation, but the 3-5-yr peak is overestimated (Fig. 8d). In comparison, the spectral peak is generally weak in ERA-40 - only the quasi-biennial variability is statistically significant at the $5 \%$ level (Figs. $8 \mathrm{e}, \mathrm{f}$ ).

\section{b. Precipitation time series at regional scale}

The above analyses show that the LMDz4 reasonably reproduces the leading modes and the associated time evolution of the interannual variability of summer monsoon rainfall over east China in terms of EOF analysis. This suggests that the variable-grid model LMDz4 is a useful tool to downscale the original ERA-40 data over China. In addition to the above broad-scale validation, one rigorous test is the ability of LMDz4 in downscaling the regional-scale rainfall changes. Figure 9 shows the precipitation time series averaged over the subregions depicted in Fig. 2b. A quantitative comparison is given in Fig. 10 as a Taylor diagram. The interannual variability of rainfall indices is reasonably reproduced-all the correlation coefficients are statistically significant at the $1 \%$ level (Fig. 10). The rainfall intensity is slightly overestimated in the Yangtze River basin (region A, Fig. 9a) but highly overestimated in the Yellow River valley (region D, Fig. 9d). For ERA-40, although the intensity of mean rainfall is close to the station observation, the interannual variability of the rainfall indices is poorly reproduced, as indicated by the low correlation coefficients shown in Fig. 10. The time series of rainfall downscaled by LMDz4 exhibits a smaller root-mean-square error, which is shown as the distance to the reference point marked "REF" on the horizontal axis, over most regions except for the region $\mathrm{D}$, that is, the Yellow River valley.

\section{Discussion}

Given the fact that the model was driven by ERA-40 data, why does the LMDz4 simulation reproduce a better interannual variability of summer rainfall over eastern China than ERA-40? The higher resolution employed in the zoom domain of LMDz4 plays an important role, because the complex terrain of the region is much better resolved, which ameliorates the regional rainfall simulation. The physical package of LMDz4 may also contribute to the improvement. The rainfall from ERA-40 is a product of an AGCM in a simulation with the model dynamics and thermodynamics constrained to observations of all sources. The horizontal resolution employed in the assimilation model is about $1.125^{\circ}$ (Uppala et al. 2005), which is unable to represent the monsoon rainfall front (Gao et al. 2006). Many previous studies have demonstrated that current state-of-the-art AGCMs, such 

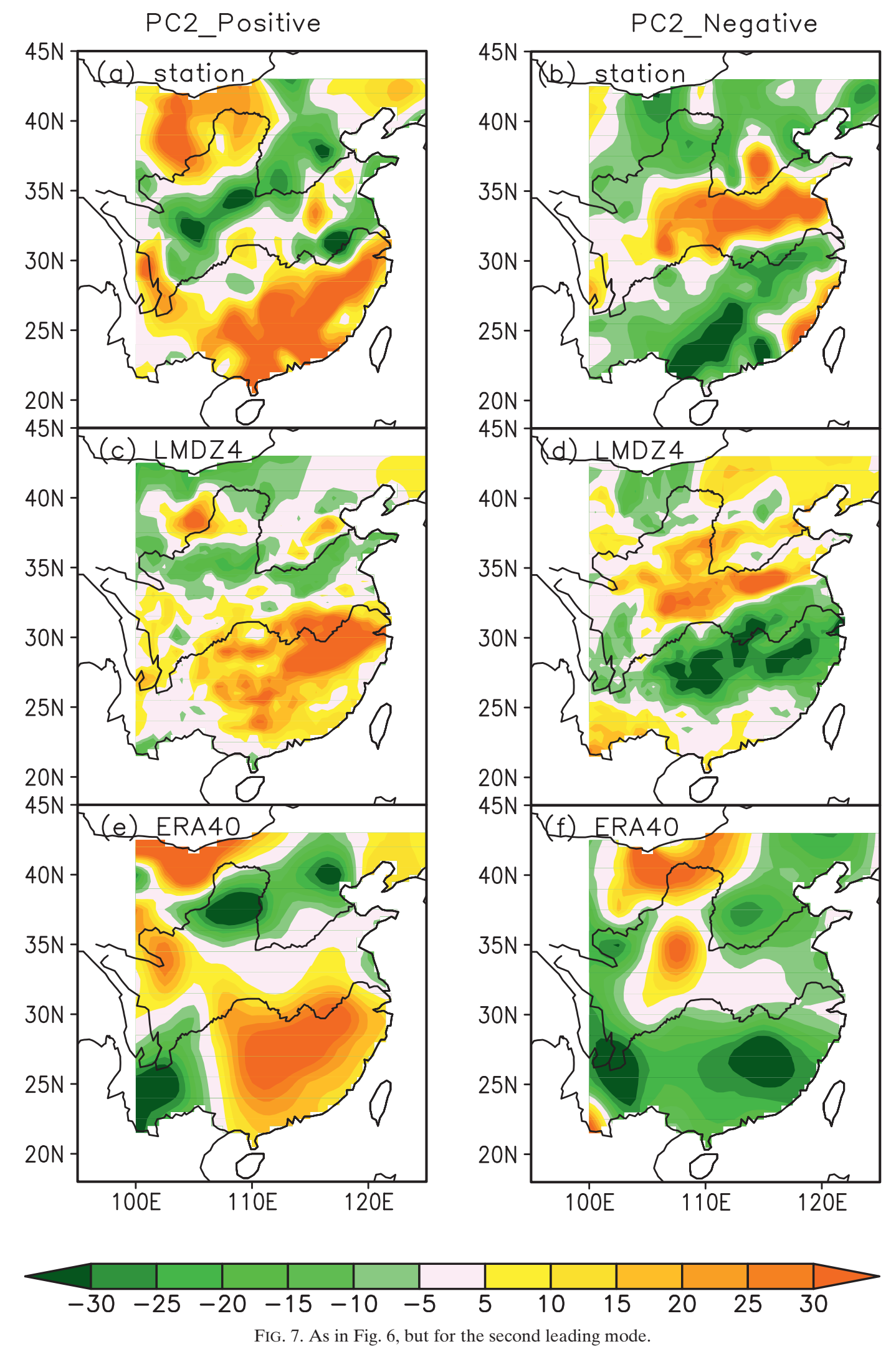

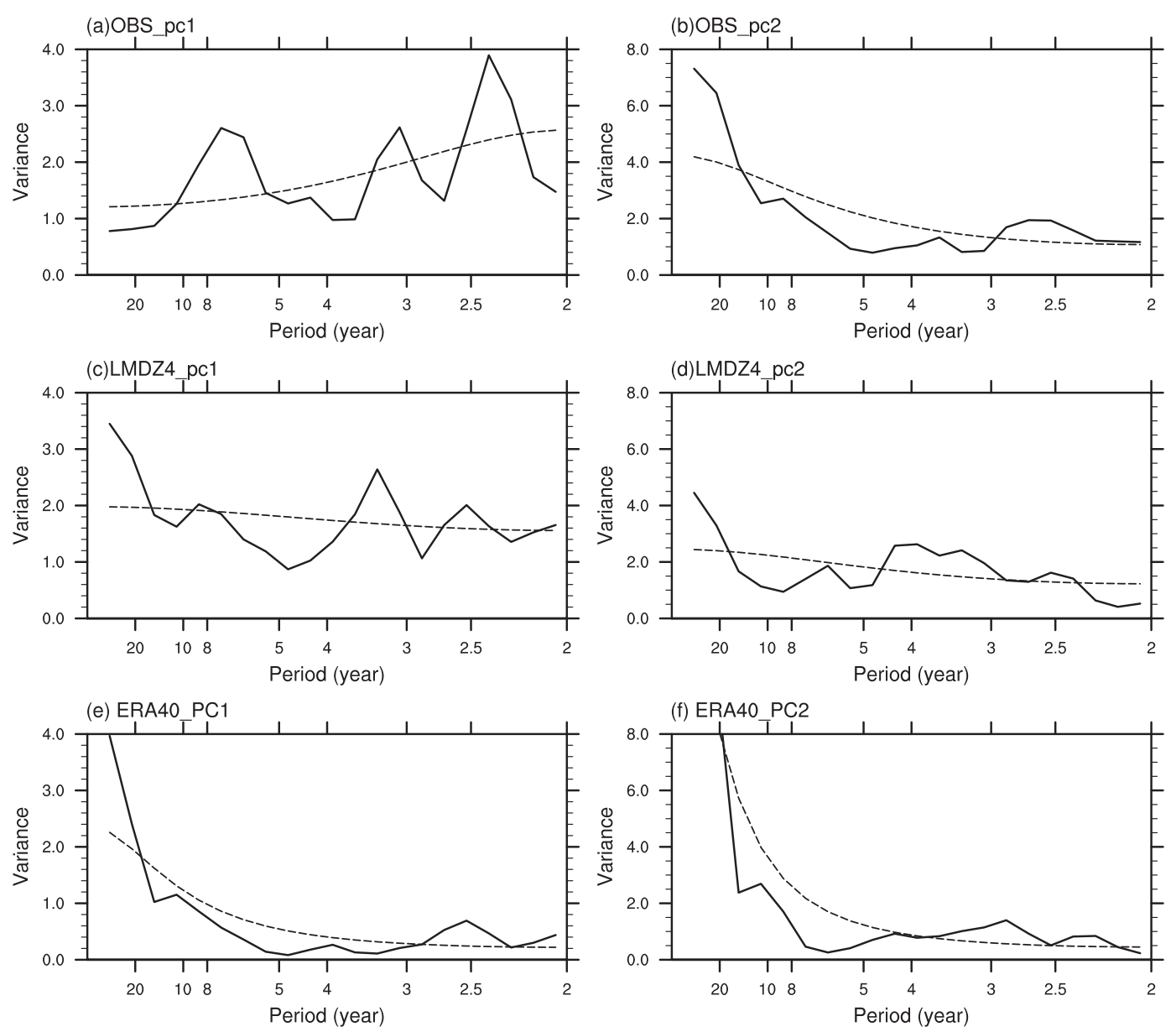

FIG. 8. Power spectra for the (left) PC1 and (right) PC2, from the (top) observation, (middle) LMDz4 simulation, and (bottom) ERA-40. Peaks over the dashed line indicate that the confidence level is $>95 \%$ against a red noise.

as Atmospheric Model Intercomparison Project (AMIP) models, are unable to correctly simulate the regional rainfall pattern over eastern Asia, although they do show significant skills in reproducing the monsoon circulation change (Wu and Zhou 2008; Zhou et al. 2008a, 2009a,b,c; Li et al. 2010).

During the processes of reanalysis, since many observed data have been assimilated into the model (Uppala et al. 2005), the output of circulation fields can be regarded as "real." Forced by these real circulation fields, the LMDz4 model can serve as a useful tool to downscale regional-scale climate fields, such as precipitation in eastern China. These regional-scale variables are important to many scientific and applied sectors, but they are unavailable in the original reanalysis dataset because of its insufficient spatial resolution.

It should be acknowledged that our results of dynamical downscaling are not perfect. In both the climate mean state and anomaly field, the centers of rainfall shift northward approximately $5^{\circ}$ in comparison with their observational counterparts. Since the convergence of water vapor is a crucial precondition for precipitation, we recognize the issue by examining water vapor transport. Since the atmospheric moisture is concentrated mainly in the low troposphere and the vertically integrated water vapor transport is dominated by the low-level atmosphere (Zhou and Yu 2005), an analysis of water vapor at $850 \mathrm{hPa}$ is enough. The climatic mean (averaged during 1958-2000) JJA surface wind and specific humidity at $850 \mathrm{hPa}$ for the reanalysis and the simulation are shown in Fig. 11. In the reanalysis, the low-level southwesterly flow transports moisture originated from the Arabian Sea, Bay of Bengal, South China Sea, and western Pacific into eastern China (Figs. 11a,b). This feature has been well documented in previous studies (Tao and Chen 1987; Zhou and Li 2002; Zhou and Yu 2005). In the simulation, while the large-scale features of surface wind (Fig. 11b) and specific humidity (Fig. 11e) are well captured, a stronger southwesterly flow bias 
(a) A Region

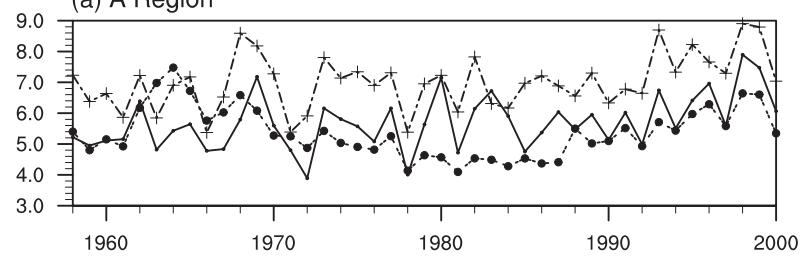

(b) B Region

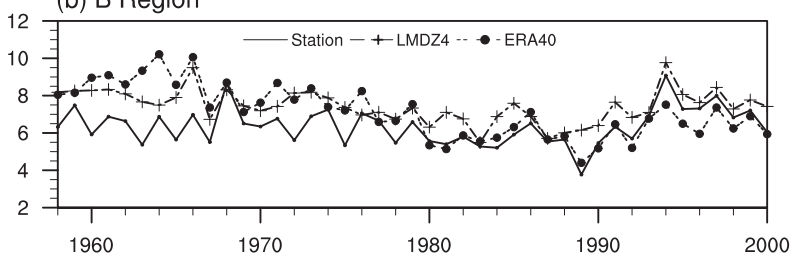

(c) C Region

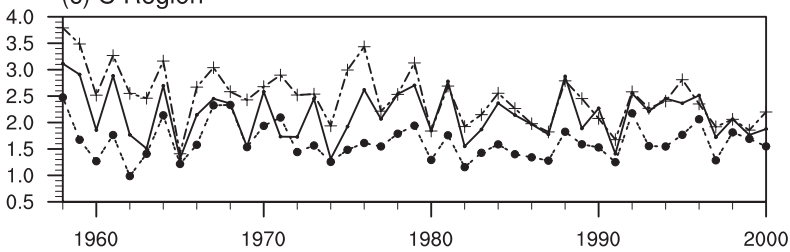

(d) D Region

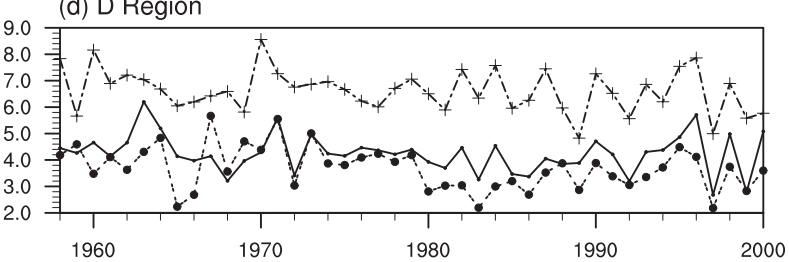

FIG. 9. Time series of precipitation $\left(\mathrm{mm} \mathrm{day}^{-1}\right)$ averaged over the four regions depicted in Fig. 2b.

located in the eastern periphery of the Tibetan plateau is evident (see the dash box in Fig. 11c), and the specific humidity over eastern China is underestimated (Fig. 11f). The stronger southwesterly flow favors a more northward transport of moisture. The drier atmosphere in the model implies that air masses need a longer time to travel farther north to reach condensation. This also favors a northward shift of the rainfall band. The wind bias along the boundary may be owing to the boundary treatment in LMDz4, which has no transition zone between the interior to exterior nudging regions. Lower humidity may have resulted from our nudging method, since the model humidity was not nudged to ERA-40 data. It is fully predicted by the model, which is a response to specified climatological SST forcing. Whether an implementation of humidity nudging would improve the result of rainfall downscaling deserves further study.

\section{Summary}

In this study, the regional rainfall variability over eastern China has been downscaled from the ERA-40

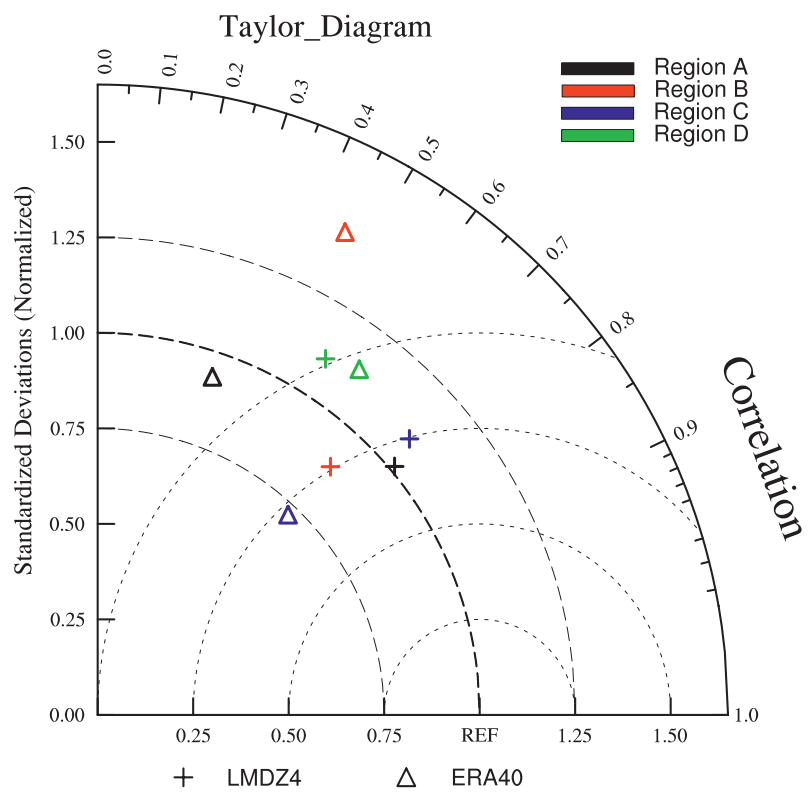

FIG. 10. Taylor diagram for the interannual variation of monsoon rainfall series shown in Fig. 9. Colors represent different regions. Crosses and triangles denote LMDz4 and ERA-40 dataset, respectively. The radial distance from the origin denotes the std ratio between each dataset and observation. The angular distance from the $x$ axis denotes the temporal correlation coefficient of rainfall series between each dataset and observation; that is, the distance between each dataset and observation quantifies how closely the rainfall index matches observation.

dataset for the period 1958-2000. The downscaling was carried out using LMDz4, a variable-grid climate model with a local zoom over eastern China. During the integration, the model wind and temperature outside the zoom domain were strongly restored to the corresponding ERA-40 variables. The added values of LMDz4 with respect to the driving ERA-40 dataset for the rainfall variable are assessed in terms of both climatology and interannual variability. The downscaled rainfall variability over eastern China is far better than the original ERA-40 data. The analysis demonstrates that the variableresolution AGCM is a useful tool in dynamical downscaling rainfall variability of eastern China. The major findings are summarized below.

The dynamical downscaling improves both the climatology and interannual variability of rainfall over eastern China. The spatial pattern of major rainbands simulated by LMDz4 is better than the forcing data (ERA-40). The dominant interannual variability modes derived from the rain gauge observation appear as a tripole pattern in EOF1 and a meridional out-of-phase change of rainfall in EOF2. The two dominant modes and their associated temporal variations downscaled by LMDz4 are better than those of ERA-40, especially for 
a) ERA40 850hPa wind

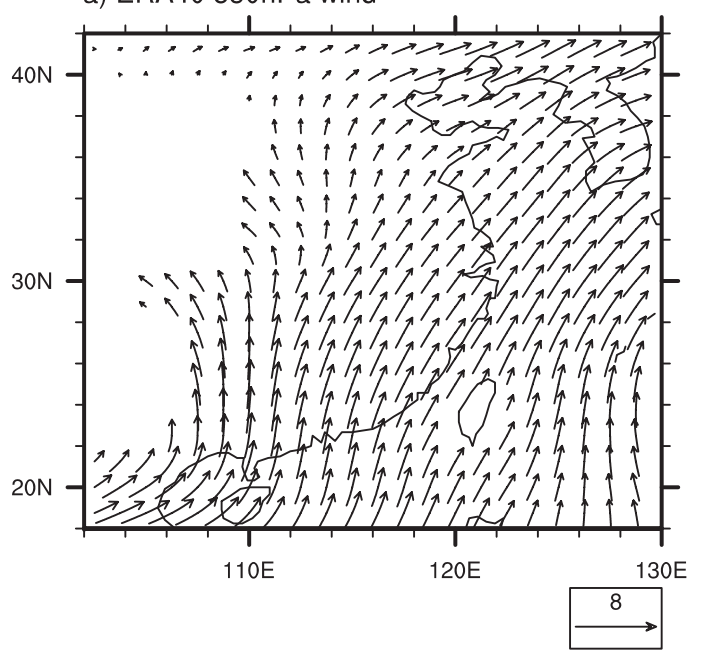

b) LMDZ4 $850 \mathrm{hPa}$ wind

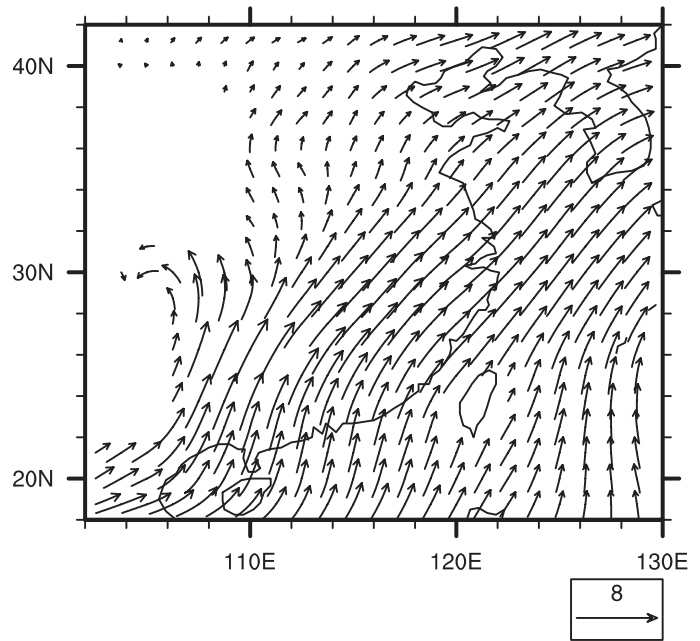

c) difference

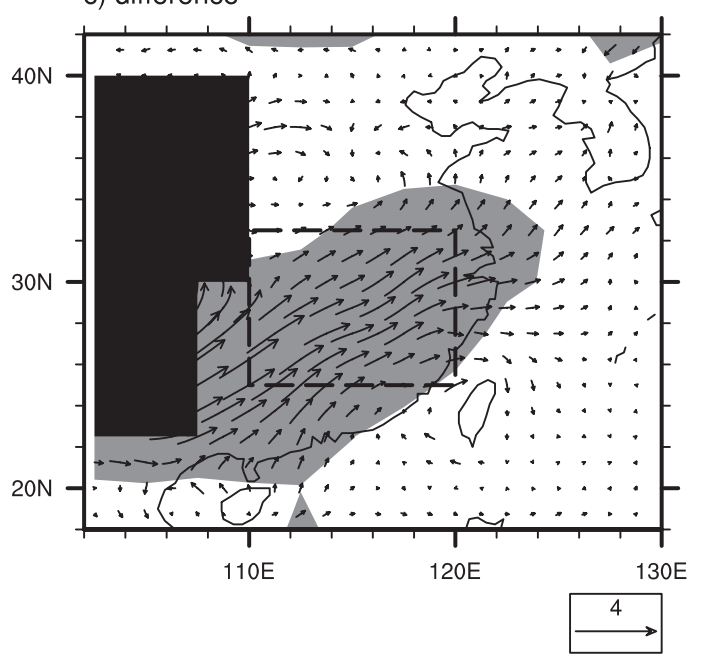

d) ERA40 Specific Humidity

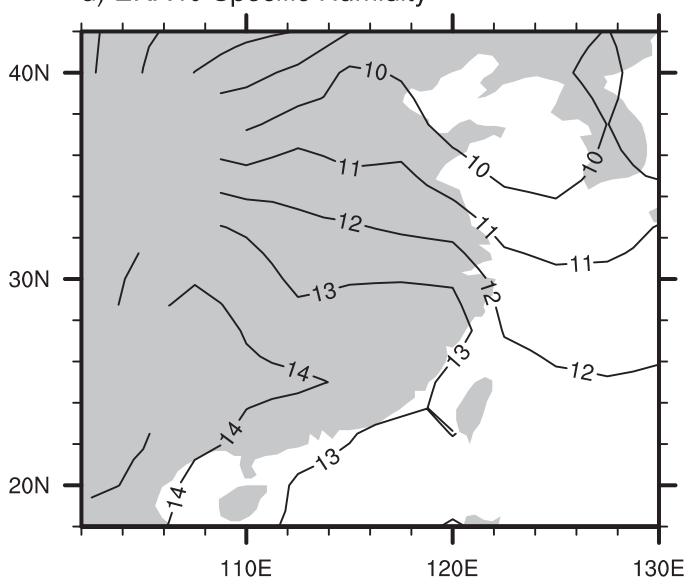

e) LMDZ4 Specific Humidity

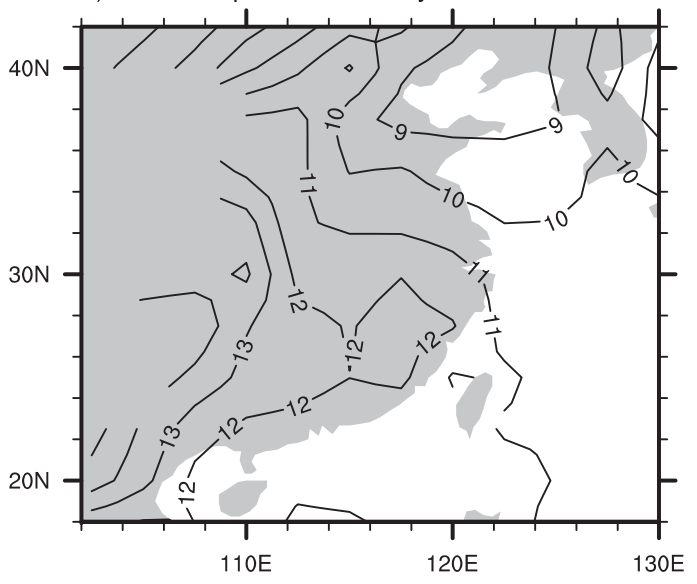

FIG. 11. JJA (a)-(c) 850-hPa wind field $\left(\mathrm{m} \mathrm{s}^{-1}\right)$ and (d)-(f) specific humidity $\left(\mathrm{g} \mathrm{kg}^{-1}\right)$ averaged during 1958-2000 from (top) ERA-40, (middle) LMDz4, and (bottom) difference (LMDz4 - ERA-40). Gray shaded areas in (c),(f) fields of difference are statistically significant at the $5 \%$ level according to a Student $t$ test. Contour interval is $1 \mathrm{~g} \mathrm{~kg}^{-1}$ in (d) and (e) and $0.4 \mathrm{~g} \mathrm{~kg}^{-1}$ in (f). Thick line in (f) denotes the zero isoline of difference between (d) and (e). The black shading in (c) and (f) denotes the topography.

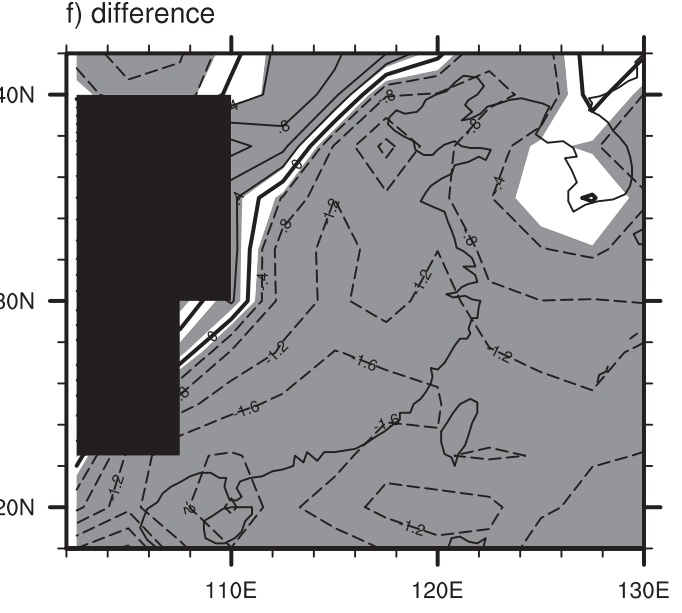


EOF1. Added values of LMDz4 are found in the constructed rainfall series at regional scales for most subregions of continental China.

The main weakness of the downscaling is the northward shift of the monsoon rain belt. This bias is evident in both the mean state and variability modes. The northward shift of the rain belt resulted from an enhanced southwest wind and a lower specific humidity over this region. The stronger southwest wind, which is partly attributed to the boundary treatment in the model, transports more water vapor to the lower reaches of the Yellow River valley. The lower specific humidity, which was not nudged to the reanalysis in the simulation, implies that the air masses need to travel farther north to reach condensation. Both favor a northward migration of the major rainband.

Acknowledgments. This work was funded by the R\&D Special Fund for Public Welfare Industry (meteorology) (GYHY200806010), National Key Technologies R\&D Program (2007BAC29B03), and by the National Natural Science Foundation of China under Grants 40890054 and 40821092 . This work is also partly supported by the Sino-French cooperative project PRA. ERA-40 data used in this study were provided by ECMWF. The helpful comments from Dr. Lei Wen, two anonymous reviewers, and the editor, Dr. James Renwick, are highly appreciated.

\section{REFERENCES}

Barstad, I., A. Sorteberg, F. Flatoy, and M. Déqué, 2009: Precipitation, temperature and wind in Norway: Dynamical downscaling of ERA40. Climate Dyn., 33, 769-776.

Bony, S., and K. A. Emanuel, 2001: A parameterization of the cloudiness associated with cumulus convection: Evaluation using TOGA COARE data. J. Atmos. Sci., 58, 3158-3183.

Chen, H., T. Zhou, R. B. Neale, X. Wu, and G. J. Zhang, 2010: Performance of the new NCAR CAM3.5 model in East Asian summer monsoon simulations: Sensitivity to modifications of the convection scheme. J. Climate, 23, 3657-3675.

Christensen, J. H., and Coauthors, 2007: Regional climate projections. Climate Change 2007: The Physical Science Basis, S. Solomon et al., Eds., Cambridge University Press, 847-940.

Ding, Y., 1994: The summer monsoon in East Asia. Monsoons over China, Y. Ding Ed., Atmospheric Sciences Library Series, Vol. 16, Kluwer Academic Publishers, 1-90.

Emanuel, K. A., 1991: A scheme for representing cumulus convection in large-scale models. J. Atmos. Sci., 48, 2313-2335.

Feng, J., and C. Fu, 2006: Inter-comparison of 10-year precipitation simulated by several RCMs for Asia. Adv. Atmos. Sci., 23, 531-542.

Fox-Rabinovitz, M., L. L. Takacs, R. C. Govindaraju, and M. J. Suarez, 2001: A variable-resolution stretched-grid general circulation model: Regional climate simulation. Mon. Wea. Rev., 129, 453-469.

_ J. Côté, B. Dugas, M. Déqué, and J. L. McGregor, 2006: Variable resolution general circulation models: Stretched-grid model intercomparison project (SGMIP). J. Geophys. Res., 111, D16104, doi:10.1029/2005JD006520.

Fu, C., and Coauthors, 2005: Regional Climate Model Intercomparison Project for Asia. Bull. Amer. Meteor. Soc., 86, 257-266.

Gao, X., Z. Zhao, Y. Ding, R. Huang, and F. Giorgi, 2001: Climate change due to greenhouse effects in China as simulated by a regional climate mode. Adv. Atmos. Sci., 18, 1224-1230.

- , - and F. Giorgi, 2002: Changes of extreme events in regional climate simulations over East Asia. Adv. Atmos. Sci., 19, 927-942.

, Y. Xu, Z. Zhao, J. S. Pal, and F. Giorgi, 2006: On the role of resolution and topography in the simulation of East Asia precipitation. Theor. Appl. Meteor., 86, 173-185.

—, Y. Shi, R. Song, F. Giorgi, Y. Wang, and D. Zhang, 2008: Reduction of future monsoon precipitation over China: Comparison between a high resolution RCM simulation and the driving GCM. Meteor. Atmos. Phys., 99, 73-86.

Gibelin, A. L., and M. Déqué, 2003: Anthropogenic climate change over the Mediterranean region simulated by a global variable resolution model. Climate Dyn., 20, 327-339.

Giorgi, F., and L. O. Mearns, 1999: Introduction to special section: Regional climate modeling revisited. J. Geophys. Res., 104, 6335-6352.

— X. Xi, and J. S. Pal, 2004: Mean, interannual variability and trends in a regional climate change experiment over Europe. I. Present-day climate (1961-1990). Climate Dyn., 22, 733756.

Goubanova, K., and L. Li, 2007: Extremes in temperature and precipitation around the Mediterranean basin in an ensemble of future climate scenario simulations. Global Planet. Change, 57, 27-42.

Han, J., and R. Zhang, 2009: The dipole mode of the summer rainfall over East China during 1958-2001. Adv. Atmos. Sci., 26, 727-735.

Hourdin, F., and Coauthors, 2006: The LMDZ4 general circulation model: Climate performance and sensitivity to parametrized physics with emphasis on tropical convection. Climate Dyn., 27, 787-813.

Hu, Z.-Z., S. Yang, and R. Wu, 2003: Long-term climate variations in China and global warming signals. J. Geophys. Res., 108, 4614, doi:10.1029/2003jd003651.

Huang, R., J. Chen, G. Huang, and Q. Zhang, 2006: The quasibiennial oscillation of summer monsoon rainfall in China and its cause (in Chinese). Chin. J. Atmos. Sci., 30, 545-560.

Kang, I.-S., and Coauthors, 2002: Intercomparison of the climatological variations of Asian summer monsoon precipitation simulated by 10 GCMs. Climate Dyn., 19, 383-395.

Krinner, G., and Coauthors, 2005: A dynamic global vegetation model for studies of the coupled atmosphere-biosphere system. Global Biogeochem. Cycles, 19, GB1015, doi:10.1029/ 2003GB002199.

Lee, D. K., and M. S. Suh, 2000: Ten-year Asian summer monsoon simulation using a regional climate model (RegCM2). J. Geophys. Res., 105, 29 565-29 577.

Le Treut, H., and Z. X. Li, 1991: Sensitivity of an atmospheric general circulation model to prescribed SST changes: Feedback effects associated with the simulation of cloud optical properties. Climate Dyn., 5, 175-187.

, - - and M. Forichon, 1994: Sensitivity of the LMD general circulation model to greenhouse forcing associated with two different cloud water parameterizations. J. Climate, 7, 1827-1841. 
Leung, L. R., L. O. Mearns, F. Giorgi, and R. L. Wilby, 2003: Regional climate research-Needs and opportunities. Bull. Amer. Meteor. Soc., 84, 89-95.

Li, H., A. Dai, T. Zhou, and J. Lu, 2010: Responses of East Asian summer monsoon to historical SST and atmospheric forcing during 1950-2000. Climate Dyn., 34, 501-514.

Li, Q., and Y. Ding, 2005: Multi-year simulation of the East Asian monsoon and precipitation in China using a regional climate model and evaluation. Acta Meteor. Sin., 19, 302-316.

Li, T., P. Liu, X. Fu, B. Wang, and G. A. Meehl, 2006: Spatiotemporal structures and mechanisms of the tropospheric biennial oscillation in the Indo-Pacific warm ocean regions. J. Climate, 19, 3070-3087.

Li, Z. X., 1999: Ensemble atmospheric GCM simulation of climate interannual variability from 1979 to 1994. J. Climate, 12, 986-1001.

Liang, X.-Z., L. Li, A. Dai, and K. E. Kunkel, 2004a: Regional climate model simulation of summer precipitation diurnal cycle over the United States. Geophys. Res. Lett., 31, L24208, doi:10.1029/2004GL021054.

, — - K. E. Kunkel, M. Ting, and J. X. L. Wang, 2004b: Regional climate model simulation of U.S. precipitation during 1982-2002. Part I: Annual cycle. J. Climate, 17, 3510-3529.

_ , M. Xu, K. E. Kunkel, G. A. Grell, and J. S. Kain, 2007: Regional climate model simulation of U.S.-Mexico summer precipitation using the optimal ensemble of two cumulus parameterizations. J. Climate, 20, 5201-5207.

Lin, C. A., L. Wen, G. Lu, Z. Wu, J. Zhang, Y. Yang, Y. Zhu, and L. Tong, 2006: Atmospheric-hydrological modeling of severe precipitation and floods in the Huaihe River basin, China. J. Hydrol., 330, 249-259.

Qian, Y., and L. R. Leung, 2007: A long-term regional simulation and observations of the hydroclimate in China. J. Geophys. Res., 112, D14104, doi:10.1029/2006JD008134.

Rayner, N. A., P. Brohan, D. E. Parker, C. K. Folland, J. J. Kennedy, M. Vanicek, T. J. Ansell, and S. F. B. Tett, 2006: Improved analyses of changes and uncertainties in sea surface temperature measured in situ since the mid-nineteenth century: The HadSST2 dataset. J. Climate, 19, 446-469.

Shi, H., R. Yu, J. Li, and T. Zhou, 2009: Development of a regional climate model (CREM) and evaluation on its simulation of summer climate over eastern China. J. Meteor. Soc. Japan, 87, 381-401.

Tao, S., and L.-X. Chen, 1987: A review of recent research on the East Asian summer monsoon in China. Monsoon Meteorology, C.-P. Chang and T. N. Krishnamurti, Eds., Oxford University Press, 60-92.
Uppala, S. M., and Coauthors, 2005: The ERA-40 Re-Analysis. Quart. J. Roy. Meteor. Soc., 131, 2961-3012.

Wang, Y., L. R. Leung, J. L. McGregor, D.-K. Lee, W.-C. Wang, Y. Ding, and F. Kimura, 2004: Regional climate modeling: Progress, challenges, and prospects. J. Meteor. Soc. Japan, 82, 1599-1628.

Wu, B., and T. Zhou, 2008: Oceanic origin of the interannual and interdecadal variability of the summertime western Pacific subtropical high. Geophys. Res. Lett., 35, L13701, doi:10.1029/ 2008 GL034584.

Yu, R., W. Li, X. Zhang, Y. Liu, Y. Yu, H. Liu, and T. Zhou, 2000: Climatic features related to eastern China summer rainfalls in the NCAR CCM3. Adv. Atmos. Sci., 17, 503-518.

Zhao, Z.-G., Ed., 1999: Summertime Floods and Droughts in China and the Associated Circulations (in Chinese). China Meteorological Press, 297 pp.

Zhou, T., and Z. Li, 2002: Simulation of the East Asian summer monsoon using a variable resolution atmospheric GCM. Climate Dyn., 19, 167-180.

- , and R. Yu, 2005: Atmospheric water vapor transport associated with typical anomalous summer rainfall patterns in China. J. Geophys. Res., 110, D08104, doi:10.1029/2004JD005413.

$\longrightarrow$, and - 2006: Twentieth-century surface air temperature over China and the globe simulated by coupled climate models. J. Climate, 19, 5843-5858.

,,$-- \mathrm{H}$. Li, and B. Wang, 2008a: Ocean forcing to changes in global monsoon precipitation over the recent half-century. J. Climate, 21, 3833-3852.

— L. Zhang, and H. Li, 2008b: Changes in global land monsoon area and total rainfall accumulation over the last half century. Geophys. Res. Lett., 35, L16707, doi:10.1029/2008GL034881.

_ B. Wu, and B. Wang, 2009a: How well do atmospheric general circulation models capture the leading modes of the interannual variability of the Asian-Australian monsoon? J. Climate, 22, 1159-1173.

— , and Coauthors, 2009b: The CLIVAR C20C Project: Which components of the Asian-Australian monsoon circulation variations are forced and reproducible? Climate Dyn., 33, 1051-1068.

— , and Coauthors, 2009c: Why the western Pacific subtropical high has extended westward since the late 1970s. J. Climate, 22, 2199-2215.

Zhu, J., and X.-Z. Liang, 2005: Regional climate model simulation of U.S. soil temperature and moisture during 1982-2002. J. Geophys. Res., 110, D24110, doi:10.1029/2005JD006472.

— and _ 2007: Regional climate model simulations of U.S. precipitation and surface air temperature during 1982-2002: Interannual variation. J. Climate, 20, 218-232. 